This is a post-peer-review, pre-copyedit version of an article published in Energy Efficiency. The final authenticated version is available online at http://dx.doi.org/10.1007/s12053-017-9578-4.

\title{
Journal Citation
}

Das, R., Richman, R., \& Brown, C. (2017). Demographic determinants of Canada's households' adoption of energy efficiency measures: observations from the Households and Environment Survey, 2013. Energy Efficiency, 1-18. https://doi.org/10.1007/s12053-017-9578-4

\section{Article Title}

Demographic determinants of Canada's households' adoption of energy efficiency measures: observations from the Households and Environment Survey, 2013

\author{
Authors \\ Dr. Runa Das ${ }^{\mathrm{a}}$ \\ Dr. Russell Richman ${ }^{\mathrm{b}}$ \\ Dr. Craig Brown ${ }^{c}$ \\ ${ }^{a}$ College of Interdisciplinary Studies \\ Royal Roads University \\ 2005 Sooke Rd., Victoria, BC, Canada, V9B 5 Y2 \\ runa.das@,royalroads.ca \\ ${ }^{\mathrm{b}}$ Department of Architectural Science \\ Ryerson University \\ 350 Victoria St., Toronto, ON, Canada, M5B 2K3 \\ richman@ryerson.ca \\ ${ }^{\mathrm{c}}$ School of Environment, Enterprise and Development \\ University of Waterloo \\ 200 University Ave. W., Waterloo, ON, Canada, N2L 3G1 \\ craig.brown@uwaterloo.ca
}

\section{Corresponding author}

Runa Das runa.das@,royalroads.ca

\begin{abstract}
In addition to a growing and aging population, Canada has experienced large shifts in its residential sector. There are more households, homes are larger with less people in them, and there are more appliances per household, all of which contribute to increased energy consumption. The present work explores the demographic determinants of residential energy efficiency adoption using the 2013 Households and Environment Survey. With binary logistic regressions, we predicted the odds of households adopting three energy-efficient actions: energy-saving lights, programmable thermostats, and changes to a dwelling following an energy audit. Although it was found that Canadian households are participating in energy efficiency, not all groups are participating equally. Similar to previous research, seniors appear to be more inclined to adopt less challenging measures such as energy-saving lights, as opposed to more intensive dwelling upgrades. Additionally, levels of education and income were positively related to the adoption of energy efficiency measures. However, the results showed household income to be less of a contributing factor for decisions regarding dwelling changes compared to the financial incentives offered via government grants. The results suggest a need to increase energy efficiency education and to continue offering financial incentives as the country increases its residential energy efficiency.
\end{abstract}

\section{Keywords}

demographics, energy efficiency, technology adoption, consumer behaviour, discrete choice, energy consumption 


\section{Introduction}

In the last two and a half decades, Canada has experienced major shifts in its residential sector. Specifically, between 1990 and 2013 the population grew by 7.5 million people, the number of households increased $40 \%$, average living space increased $17 \%$, and the average number of individuals per household fell from 2.8 in 1990 to 2.5 in 2013 (Natural Resources Canada, 2016). Further, efficiency gains and overall reductions in energy use from major appliances were outweighed by the rapid growth of minor appliances such as cell phones, personal computers, TVs, and video game consoles (Natural Resources Canada, 2016).

The impact of these changes is already being seen. That is, despite improvements in energy efficiency, energy use between 1990 and 2013 increased nearly 7\% (Natural Resources Canada, 2016). Assuming that Canadians will continue to use a lot of energy and that the above trends in the residential sector persist, energy efficiency is an issue of utmost importance. As such, we are motivated by the desire to understand the actions being taken by individuals and households to use energy more efficiently.

According to Gardner and Stern (2008), households can significantly reduce their energy consumption by changing their choice of technologies or using existing technologies. Further the authors suggest that individuals and households can reduce their energy consumption without making compromises to lifestyle (2008). As a result, the authors have determined a "short list" of the most effective actions that households can take to reduce energy consumption, with these actions varying in cost, feasibility, and target audience (i.e., homeowners versus all individuals) (Gardner \& Stern, 2008). Since the "list's" publication, it appears that little has been released by way of a researched guide for households to manage their energy usage. As such, we used this list to influence our selection of three actions that have the potential for increasing household energy efficiency, and because of their availability to all Canadians. It should be noted that we are interested in all effective actions to reduce household energy use, and therefore all measures of energy efficiency; however, our focus on the three specific actions here related to data availability and to actions that Canadians were recently surveyed on.

First, we are concerned with the adoption of technology and specifically the adoption of energy-saving lights. Energy-efficient lights have undergone major changes in technology, which have improved their efficiency (Hicks \& Theis, 2014). According to Gardner and Stern's list (2008) for individuals and households, replacing 85\% of all incandescent light bulbs with equally bright compact fluorescent (CFL) bulbs can lead to 4\% in energy savings. Further, light-emitting diodes (LEDs) are up to $75 \%$ more efficient compared to incandescent light bulbs and last 26 times longer (Toronto Hydro, n.d.). Our concern with energy-saving lights also stems from Canada's phase out of 60- and 40-W incandescent light bulbs, an extension of the former ban on 75- and 100-W light bulbs (Blackwell, 2015).

Gardner and Stern (2008) also prioritize turning thermostats down during the heating season and turning thermostats up during the cooling season. The heating season in Canada varies and can last up to 10 months in some parts of the country. Adjusting thermostat temperatures is thus one way Canadians can save on energy use, given that adjusting set points can save on heating and cooling (e.g., US Department of Energy, n.d.). Further, these behaviors are particularly relevant for Canadians given that approximately $63 \%$ of Canadian residential energy use is for space heating (Natural Resources Canada, 2016). With respect to cooling, occupied cooled floor space has increased from $22 \%$ in 1990 to $46 \%$ in 2013 . Even more, because of rising temperatures, the energy required to cool homes rose 95\% from 1990 to 2013 (Natural Resources Canada, 2016). Although heating and cooling can be adjusted manually, we are interested in technology adoption and we therefore focus our attention on the adoption of programmable thermostats. Thermostats have the important function of regulating temperature but many features and functions have emerged to facilitate their energy-saving role (Peffer, Pritoni, Meier, Aragon, \& Perry, 2011).

Last, we want to determine whether or not households are making changes to their dwellings as suggested to them through the results of home energy audits. Home energy audits can help homeowners better understand the extent to which improvements can be made to their dwelling as well as the specific improvements that can be made (Hoicka, Parker, \& Andrey, 2014). In particular, home energy audits can inform households about their current energy usage, wastage, and provide options for saving energy (Gamtessa, 2013). These can involve investments in low hanging fruit, such as caulking and weather stripping, or can include more onerous renovations and upgrades, such as installing attic insulation and upgrading heating and cooling units.

By adopting measures of energy efficiency, Canadian households can make a meaningful contribution to reducing energy use and therefore to greenhouse gas reductions. In particular, over the 1990-2013 period, household energy use in Canada increased $6.5 \%$ and would have increased by $51 \%$ without the use of energy efficiency improvements (Natural Resources Canada, 2016). Furthermore, energy efficiency improvements, including retrofits as well as the adoption of energy efficiency items such as furnaces, appliances, lighting, and air conditioning, allowed Canadians to save \$12 billion in energy costs and 27 MT in greenhouse gas emissions in 2013 (Natural 
Resources Canada, 2016). Moreover, households have been recognized as important units of analysis for the examination of environmental behavior (Reid, Sutton, \& Hunter, 2010), here energy efficiency.

Present demographic shifts in the residential sector, however, may be affecting the energy efficiency choices being made by Canadians. The overarching goal of this paper was to therefore explore the demographic determinants behind households' choices regarding the adoption of energy-efficient technology and energy-efficient dwelling changes using the national Households and Environment Survey. This research contributes to the energy efficiency literature by providing empirical evidence to support the relationship between demographics and the adoption of energy efficiency measures, as well as the implications of these relationships. Although several studies have examined the relationship between demographics and energy use (for a review see Frederiks, Stenner, \& Hobman, 2015), less research has been conducted within the altogether different sphere of energy efficiency (versus consumption). Moreover, by improving our understanding of the link between demographic variables and the uptake of energy efficiency measures, more effective and targeted residential policies can potentially follow. Thus, this research is relevant to researchers, policymakers, decision-makers, and industry.

The paper continues as follows: the "Demographic factors related to energy efficiency" section presents background literature on the demographic factors related to measures of energy efficiency, paying special attention to the demographic variables included in the Households and Environment Survey, 2013. The "Dataset and variables" and "Method of analysis and diagnostics" sections present our dataset, variable information, our method of analysis, and modeling diagnostics. The "Results and discussion" section presents the results of our logistic regressions predicting the odds of households adopting energy-saving lights, programmable thermostats, and whether or not households made changes to their dwellings following an energy audit. We present an overview of the findings and their implications in the "Conclusion" section, followed by concluding remarks.

\section{Demographic factors related to energy efficiency}

The area of energy studies has been rapidly expanding, with a growing body of research designed to explore the determinants of household energy consumption. Many important factors have been identified as contributing to this phenomenon and include external factors, such as policies, as well as individual level factors, such as demographics. These studies are important because they allow for a more holistic understanding of household consumption that can further complement technical understandings of household energy consumption (i.e., building science). In a similar manner, greater scope is needed in the area of energy efficiency research and, specifically, the determinants of household energy efficiency. By including demographics in examinations of energy efficiency, it will be possible to gain a deeper understanding of the people adopting measures of energy efficiency - important insights for knowing what measures are working and for whom. Further, such insights may be able to answer the question why certain measures of energy efficiency are being adopted. In the following section, we review previous research examining the relationship between demographic characteristics and the adoption of energy efficiency. Though research in this specific area is limited, recent findings are insightful.

Age and household composition

Although some studies have examined how age and household composition affect energy efficiency practices, the results are mixed. Using a double-hurdle model, Mills and Schleich (2010) operationalized the adoption of CFLs as the outcome of discrete market entry decisions as well as adoption intensity (i.e., the intensity of CFL purchases for home use). The researchers found that market entry is positively associated for households with children under 6 years of age and retirees (Mills \& Schleich, 2010). With respect to adoption intensity, the researchers found that age has a positive impact on adoption intensity up to 62 years of age, and then a negative impact. The presence of children had no impact on adoption intensity (Mills \& Schleich, 2010). In another study, using a dataset of approximately 5000 households in 10 EU countries and Norway, Mills and Schleich (2012) examined the adoption of CFLs, exclusively, as well as the adoption of technology consisting of energy-efficient appliances, office equipment, and lighting (i.e., their energy-efficient technology index). With respect to CFL adoption, the authors found that households consisting of young children (i.e., persons less than 12 years of age) are associated with increased CFL adoption (Mils \& Schleich, 2012). With respect to their technology index, the authors found a distinct pattern for age and household composition; households composed of middle age adults (persons between 19 and 65 years of age) with young children were linked to higher rates of technology adoption whereas households composed of persons 65 years of age and older were linked to lower rates of technology adoption (Mills \& Schleich, 2012). Similarly, in their study examining the adoption of innovative heating systems, Mahapatra and Gustavsson (2008) found that plans to install new heating systems decreased as homeowner age increased. Using a discrete choice model for examining the determinants of residential heating systems, Michelsen and Madlener (2012) found 
some evidence of older homeowners preferring older types of heating systems, such as oil-fired systems, while younger homeowners were found to be more open to newer types of heating systems, such as heat pumps.

Sardianou and Genoudi (2013) surveyed people in Greece on their willingness to adopt renewable energy systems for their homes and found that middle-aged persons were more willing to adopt renewable energy systems than younger people.

More recently, Ameli and Brandt (2015) examined the OECD Survey on Household Environmental Behavior and Attitudes in order to examine the determinants of households' investment in energy efficiency and renewables. This is a fairly large survey with 12,000 respondents and a sample that was stratified in each country according to age, gender, region and socio-economics (Ameli \& Brandt, 2015). This is an interesting survey as it covers several different types of energy efficiency actions with respondents being asked whether or not they invested in top-rated energy efficiency appliances, energy-saving lights, energy-efficient windows, thermal insulation for their walls or roof, heating thermostats, solar panels for electricity or hot water, or ground source heat pumps (Ameli \& Brandt, 2015). For most of these energy efficiency actions the age of the respondent appears to be important; the probability of investments in light bulbs, heat thermostats, thermal insulation and energy-efficient windows increases with age, while the probability to choose heat pumps decreases with age (Ameli \& Brandt, 2015).

Generally, these findings appear to demonstrate that measures of energy efficiency are being adopted across age groups and types of households. However, older individuals seem less likely to adopt or invest in technologies or measures that are more novel.

\section{Level of education}

Less work has been done in terms of investigating the effects of levels of education on technology adoption and retrofit behavior (i.e., upgrades and changes made to dwellings resulting from energy audits). However, several of the above studies that have examined age and household composition have also examined the effect of education on the adoption of energy efficiency measures. Mills and Schleich (2012) measured education as the highest level of education attained by any member of a household, with the possible categories being high school, trade or vocational school, and university; members with no high school education served as the reference group. Using ordinary least squares regressions, they found that the adoption of CFLs increased for households having high school, trade or vocational school, or university educated members (Mills and Schleich, 2012). However, the effect for having CFLs for those having a university level of education, in comparison to those having a high school, trade or vocational level of education, did not appear to be substantial (Mills and Schleich, 2012). For their technology index examining the adoption of energy-efficient appliances, office equipment, and lights, they found that households increased their use of energy-efficient technologies when the most educated household member had completed high school, trade or vocational school, and university relative to households in which members had not completed high school (Mills \& Schleich, 2012). Further, the authors found the effect of a university level of education on energy-efficient technology adoption to be larger than the effects of having a high school or trade or vocational school level of education (Mills \& Schleich, 2012). Similarly, Sardianou and Genoudi's (2013) survey on the willingness of residents to adopt renewables in the residential sector indicated that more educated consumers were more likely to implement renewables than less educated consumers. Michelsen and Madlener (2012) measured education by determining whether or not households have university-level educated members and found that these types of households were more interested in heating systems such as gas-fired condensing boilers with thermal support and heat pumps, and less interested in wood pellet-fired boilers. These findings provide support for higher levels of education and energy efficiency adoption, and contrast findings on the relationship between levels of education and energy use, which appear to be mixed. In particular, studies have found no significant relationship between education level and household energy use (Gatersleben, Steg, \& Vlek, 2002), or a weak relationship (Tonn \& Berry, 1986).

Income

Income appears to be strongly related to household energy consumption. In particular, many studies have found significant relationships between household income and household energy use (e.g., Abrahamse \& Steg, 2011; Biesiot \& Noorman, 1999; Poortinga, Steg, Vlek, \& Wiersma, 2003; Ritchie, Mcdougall, \& Claxton, 1981), suggesting that higher income households consume more energy than lower income households. But higher-income households also have the potential to spend more and therefore have the potential to adopt more energy-saving measures than lower-income households (Abrahamse \& Steg, 2009).

In their study on CFL market entry and adoption intensity, Mills and Schleich (2010) found that lower 
income groups showed negative associations with market entrance while higher-income groups did not differ significantly from their median-income group. Further, the researchers suggest that households are constrained by income only at the very low income levels (Mills \& Schleich, 2010). With respect to adoption intensity, Mills and Schleich (2010) found that lower-income groups tended to adopt more intensively than higher income groups and suggest that this effect may be the result of electricity comprising a larger share of overall household expenditures. In other words, while the payback period remains constant for all income groups, the savings-to-income ratio appears to be more compelling for low-income individuals.

In their study sampling OECD countries, Ameli and Brandt (2015) found that many types of investments depend positively on income: top-rated energy efficiency appliances, energy-efficient windows, thermal insulation for walls or roof, and heating thermostats. For light bulbs, solar panels, and heat pumps, household income was not significant and therefore not included in their preferred empirical models (Ameli \& Brandt, 2015).

For more intensive measures of energy efficiency, previous studies also suggest that household income is important. Nair, Gustavsson, and Mahapatra (2010) found that homeowners with higher household incomes were more likely to adopt building efficiency measures. Michelsen and Madlener (2012) found household income to have a positive impact on the probability of households to choose either gas-fired condensing boilers with thermal support or heat pumps, while it had a negative impact on the probability to choose oil-fired systems or wood pellet-fired boilers (i.e., solid fuel heating systems). That is, the probability to choose oil-fired and wood pellet-fired boilers decreased for households with higher incomes. Gardner and Stern (2008), indicate that energy efficiency behaviors are more impactful than curtailment behaviors and that the former is preferable for higher income households (Stern \& Gardner, 1981; Poortinga et al., 2003).

Though household income may be a pressing issue for investing or not investing in measures of energy efficiency, motivations for investment may depend on context. In a revealing study, Brounen, Kok, and Quigley (2013) found that elderly individuals made choices based on their life stage and not solely on finances. In particular, study participants were presented with a hypothetical situation in which they were homeowners with broken heating systems. They were asked to make a decision regarding the replacement of the broken heating system and were presented with two options. Option 1 had a higher initial price but a shorter payback period whereas option 2 had a lower initial price but a longer payback period. Brounen et al. (2013) found that older participants, persons who were 70 years of age and older, chose the heating system with the lower initial cost but with the longer payback period. Interestingly, however, is that several participants rationalized their decision by claiming that they expected to live shorter lives than the payback period of the more expensive system. What initially seemed to be the more irrational decision is, in actuality, a thoughtful decision that accounts for life expectancy.

\section{Household size}

For most studies on household energy use, household size, and specifically the number of persons per household, is typically included as a control variable. Generally, a positive relationship exists between household size and household energy use such that, as the number of persons per household increases so does the amount of total household energy consumption (e.g., Abrahamse \& Steg, 2011; Benders, Kok, Moll, Wiersma, \& Noorman, 2006; Brown, Gorgolewsk, \& Goodwill, 2015). According to Frederiks et al. (2015), this may be because larger households may use and have more appliances, have more disposable income to spend on energy consumption, and have greater demand requirements such as cooking and cleaning. However, when energy use is measured per person the relationship appears to be reversed, with one-person households using the highest amount of energy per capita (Holloway \& Bunker, 2006). The question then becomes: how does household size affect the adoption of energy efficiency? There is limited study on this, however, Mills and Schleich (2010) found that both the market entry of CFLs as well as its intensity of adoption increases as the number of household members increases. Ameli and Brandt (2015) also found that the number of household members is positively related to investments in solar panels and light bulbs. It is possible, that larger households may have more disposable income to invest in energy efficiency. Further, it is possible that larger households are more motivated to be energy efficient given that the number of persons per household increases the total amount of household energy consumption.

\section{Dataset and variables}

Data for this analysis came from the Households and the Environment Survey (HES), 2013, which is a nation-wide survey administered by Statistics Canada used to collect data on the environmental behaviors and practices of households. This survey was previously administered in 1991, 1994, 2006, 2007, 2009, and 2011. The current study used data from the public use microdata file, which was collected between September and December 2013. The survey included questions on various environmental topics including but not limited to recycling, composting, 
consumption and conservation of water, and purchasing decisions. Our particular interest related to questions on household energy use and home heating and cooling, including several measures of energy efficiency.

This is a sample survey with a cross-sectional design consisting of households selected from respondents to the Canadian Community Health Survey, which generated its sample using an area frame, a list frame of telephone numbers, and random digit dialing. Data were collected from representatives of selected households using Computer Assisted Telephone Interviewing. The initial 2013 HES sample size consisted of 31,962 dwellings and the response rate for this survey was $75.4 \%$. Data are weighted to compensate for the probability of selection and to match Canadian households with the population in reference to province and household size.

We are interested in the energy efficiency activities of Canadians, and therefore, our dependent variables were drawn from the energy efficiency variables found in the 2013 HES. First, in order to examine the lighting choices of Canadians, we examined whether or not households had any of five energy-saving lighting types (i.e., compact fluorescents, fluorescent tubes, halogen lights, LED holiday lights, and other types of LEDs). This dichotomous variable is composed of two groups: households who responded to having any or all of these lighting types and households who responded to not having any of these energy-saving lighting types. Second, we examined the adoption of programmable thermostats. Programmable thermostats can be defined as a device that automatically controls the temperature within a room by reacting to the room's temperature and can be set to certain temperatures according to the time of day (Natural Resources Canada, n.d.). In particular, households were asked, "Is your main thermostat programmable?" We focused our attention on whether or not households had programmable thermostats rather than whether or not households were using the programmable thermostats. While adoption is relatively straightforward - and indicative of a promising behavior - determining whether or not a thermostat is being used optimally requires more detailed apparatus (e.g., logging functions on thermostats). With the third dependent variable we examined whether or not changes were made to a household's dwelling as a result of an energy audit. Therefore, we were not only interested in whether or not households conducted energy audits, but if they made changes because of the audits. Given that the changes resulting from an energy audit are more likely to substantially reduce energy use than an energy audit itself, we believe that concentrating on these changes to be more valuable. We do acknowledge, however, that the action of conducting an energy audit is a very important and crucial first step. This third variable, in comparison to the other dependent variables, consisted of a much smaller subsample comprising only those households who responded "yes" to having conducted an energy audit first.

For the first predictor variable, and due to the limitations of the dataset, we could not disaggregate the age variable to use it, strictly, as a meaningful predictor variable. That is, this predictor captured both age and household composition. Our classification method is thus somewhat similar to other studies using the concept of the family life cycle (e.g., Fritzsche, 1981) but pertains more to household type and composition such as in Mills and Schleich (2012). Specifically, categories were composed of children (persons 0 to 17 years of age), middle age adults (persons 18 to 64 years of age), and seniors (persons 65 years of age and older). Households composed of middle age adults with children and seniors were combined with households composed only of seniors and children, given that the latter group was very small. Other demographic predictors included the highest level of education ever completed by any member of the household, household income, and household size. It should be noted that this public use microdata file measured income using three categories: less than $\$ 40,000, \$ 40,000$ to $\$ 80,000$, and more than $\$ 80,000$. We were thus limited to these categories in our analyses.

Control variables were included based on research suggesting their potential impact on energy consumption and conservation (e.g., Abrahamse \& Steg, 2009; Brounen et al., 2013; Fritzsche, 1981; Macey, 1988; Mills \& Schleich, 2012; Sardianou \& Genoudi, 2013; Warriner, 1981). The following control variables were included in the models: province of residence, homeownership, dwelling type, tenure (i.e., duration of residence), vintage (i.e., age of dwelling), type of main heating equipment, air conditioning, and whether or not a government grant was received as part of a home energy retrofit program. Table 1 provides a summary of the measurement of all variables. 
Table 1 List of variables and measurement

\begin{tabular}{|c|c|}
\hline Variable & Measurement \\
\hline Energy saving lights & $\begin{array}{l}\text { Dichotomous variable: } 0=\text { does not have any energy saving lights } / 1=\text { has energy } \\
\text { saving light(s) }\end{array}$ \\
\hline Programmable thermostat & Dichotomous variable: $0=$ not programmable/1=programmable \\
\hline $\begin{array}{l}\text { Dwelling changes } \\
\text { resulting from an energy } \\
\text { audit }\end{array}$ & Dichotomous variable: $0=$ no changes made $/ 1=$ changes made \\
\hline Household composition & $\begin{array}{l}\text { Dummy variables: middle age adults only (reference)/middle age adults with } \\
\text { children/middle age adults, children, and seniors /seniors only }\end{array}$ \\
\hline Education & $\begin{array}{l}\text { Dummy variables: high school or less/some postsecondary, postsecondary } \\
\text { certificate, or diploma/university (reference) }\end{array}$ \\
\hline Household income & $\begin{array}{l}\text { Dummy variables: less than } \$ 40,000 / \$ 40,000 \text { to less than } \$ 80,000 / \$ 80,000 \text { or more } \\
\text { (reference) }\end{array}$ \\
\hline Household size & $\begin{array}{l}\text { Dummy variables: one person (reference)/two persons/three persons/four or more } \\
\text { persons }\end{array}$ \\
\hline Province of residence & Dummy variables: Maritimes/Prairies/Quebec/British Columbia/Ontario (reference) \\
\hline Homeowner & Dichotomous variable: $0=$ no $/ 1=$ yes \\
\hline Dwelling type & $\begin{array}{l}\text { Dichotomous variable: } 0=\text { low or high-rise apartment } / 1=\text { single detached, double, } \\
\text { row, or terrace, duplex, institutions, hotels, rooming/lodge house, camps, and } \\
\text { mobile homes }{ }^{\text {a }}\end{array}$ \\
\hline Tenure & $\begin{array}{l}\text { Dummy variables: less than } 5 \text { years (reference) } / 5 \text { to less than } 10 \text { years } / 10 \text { to less } \\
\text { than } 20 \text { years } / 20 \text { to less than } 30 \text { years } / 30 \text { years and more }\end{array}$ \\
\hline Vintage & $\begin{array}{l}\text { Dummy variables: before 1960/ between } 1961 \text { and 1977/ between } 1978 \text { and 1995/ } \\
\text { after } 1996 \text { (reference) }\end{array}$ \\
\hline Main heating equipment & $\begin{array}{l}\text { Dummy variables: forced air furnace (reference)/electric baseboards/heating stove, } \\
\text { heat pump, or electric radiant heating/boiler with hot water or steam }\end{array}$ \\
\hline Air conditioning & Dichotomous variable: $0=$ no $/ 1=$ yes \\
\hline Government grant & Dichotomous variable: $0=$ no/ $1=$ yes \\
\hline
\end{tabular}

${ }^{a}$ This public use microdata file could not be disaggregated further. It should be noted that in 2011, of the 13,230,610 Canadian households, single detached houses comprised 7,239,150 of total households, apartments larger than five storeys comprised 1,234,770 of total households, and semis, row housing, apartments in duplex or apartments with less than five storeys comprised 4,573,185 households. The remainder was classified as movable dwellings (Statistics Canada, 2011).

\section{Method of analysis and diagnostics}

All analyses were carried out using SPSS version 21. To examine the effect of the predictor variables (i.e., demographic variables) on the dichotomous measures of energy efficiency, binary logistic regressions were used. Specifically, three separate binary logistic regressions were conducted on each of the following dependent variables: energy-saving lights, programmable thermostats, and dwelling changes resulting from an energy audit.

Multicollinearity was assessed, as several variables have the potential to be related. Specifically, variance inflation factors (VIFs) and tolerance levels were assessed with respect to suggested values in the literature (Pan \& Jackson, 2008; Rogerson, 2001). Results were within limits with our lowest tolerance being equal to 0.27 . Missing data were also carefully examined. With the exception of four variables, the variables in the models have less than $5 \%$ of cases missing for an unknown reason and thus were not significant concerns. Approximately $6 \%$ of cases were missing for the programmable thermostat variable. However, almost all of these cases were valid skips and belonged to respondents who did not have thermostats. Further, approximately $6 \%$ of respondents did not state whether or not any changes were made to their dwelling as a result of an energy audit and whether or not a government grant was received as part of a home energy retrofit program. Upon closer inspection, we found that those who did not state their responses to these two questions previously answered that they were unaware whether or not an energy audit was conducted for their dwelling. With respect to income, 3778 respondents did not state their household income and a missing cases analysis revealed significant differences. However, given that significance is almost always obtained with large samples, Cramer's $V$ was additionally used to measure the strength of the missing cases analysis. With respect to household type, we found that households composed of middle age adults only 
reported their household income less than the other household types, $p<0.001$, Cramer's $V=0.15$. Households with members completing university as well as two-person households were also less likely to report their income, $p<$ 0.001 , Cramer's $V=0.08$, for both. We also found that households in Ontario reported their income less than households in all other provinces, $p<0.001$, Cramer's $V=0.09$. Last, households living in their dwelling between 10 and less than 20 years as well as households using a forced air furnace for their main heating equipment reported their income less than households not belonging in these groups, $p<0.001$, Cramer's $V=0.08$ and 0.04 , respectively. Although the measures of association found here can be categorized as negligible to weak (i.e., Cramer's $V$ can have values between 0 and 1 with values closer to 1 being stronger; Rea \& Parker, 2014), some caution should be exercised when interpreting the effects of the demographic variables, province of residence, tenure, main heating equipment, and household income, given the ways in which the missing cases may be biasing these estimates. Table 2 provides summary statistics for all the variables used in all three logistic regressions. 
Table 2 Descriptive statistics for full sample of HES respondents $(N=22,238)$

\begin{tabular}{|c|c|c|c|}
\hline Variable & Categories & Percentage $^{\mathrm{a}}$ & $\begin{array}{c}\text { Valid } \\
\text { Responses }\end{array}$ \\
\hline \multirow[t]{2}{*}{ Energy saving lights } & Has energy saving lights & $89.4 \%$ & 22,151 \\
\hline & Does not have energy saving lights & $10.6 \%$ & \\
\hline \multirow[t]{2}{*}{ Programmable thermostat } & Programmable & $57.1 \%$ & 20,919 \\
\hline & Not programmable & $42.9 \%$ & \\
\hline \multirow{2}{*}{$\begin{array}{l}\text { Dwelling changes from an energy } \\
\text { audit }\end{array}$} & Changes made & $62.9 \%$ & 3,429 \\
\hline & No changes made & $37.9 \%$ & \\
\hline \multirow{4}{*}{ Household composition } & Middle age adults only & $46.5 \%$ & 22,201 \\
\hline & Middle age adults with children & $26.9 \%$ & \\
\hline & Middle age adults, children, and seniors & $9.0 \%$ & \\
\hline & Seniors only & $17.6 \%$ & \\
\hline \multirow[t]{3}{*}{ Education } & High school or less & $22.2 \%$ & 21,966 \\
\hline & $\begin{array}{l}\text { Some postsecondary, postsecondary } \\
\text { certificate, or diploma }\end{array}$ & $27.9 \%$ & \\
\hline & University & $49.9 \%$ & \\
\hline \multirow[t]{3}{*}{ Household income } & Less than $\$ 40,000$ & $24.5 \%$ & 18,460 \\
\hline & $\$ 40,000$ to less than $\$ 80,000$ & $33.3 \%$ & \\
\hline & $\$ 80,000$ or more & $42.3 \%$ & \\
\hline \multirow[t]{4}{*}{ Household size } & One person & $25.8 \%$ & 22,226 \\
\hline & Two persons & $35.0 \%$ & \\
\hline & Three persons & $15.4 \%$ & \\
\hline & Four or more persons & $23.8 \%$ & \\
\hline \multirow[t]{5}{*}{ Province of residence } & Maritimes & $7.1 \%$ & 22,238 \\
\hline & Prairies & $17.2 \%$ & \\
\hline & Quebec & $24.9 \%$ & \\
\hline & British Columbia & $37.3 \%$ & \\
\hline & Ontario & $13.4 \%$ & \\
\hline \multirow[t]{2}{*}{ Homeownership } & Own home & $72.1 \%$ & 22,238 \\
\hline & Does not own home & $27.9 \%$ & \\
\hline \multirow{2}{*}{ Dwelling type } & Low/high-rise apartment & $24.0 \%$ & 21,456 \\
\hline & All dwellings, other than apartments & $76.0 \%$ & \\
\hline \multirow[t]{5}{*}{ Tenure } & Less than 5 years & $28.0 \%$ & 22,189 \\
\hline & 5 to less than 10 years & $23.4 \%$ & \\
\hline & 10 to less than 20 years & $25.1 \%$ & \\
\hline & 20 to less than 30 years & $12.6 \%$ & \\
\hline & 30 years and more & $10.9 \%$ & \\
\hline \multirow[t]{4}{*}{ Vintage } & Before 1960 & $24.2 \%$ & 21,266 \\
\hline & Between 1961 and 1977 & $23.0 \%$ & \\
\hline & Between 1978 and 1995 & $28.4 \%$ & \\
\hline & After 1996 & $24.4 \%$ & \\
\hline \multirow[t]{4}{*}{ Main heating equipment } & Forced air furnace & $53.7 \%$ & 22,060 \\
\hline & Electric baseboards & $28.5 \%$ & \\
\hline & Heating stove, heat pump, radiant heating & $8.6 \%$ & \\
\hline & Boiler with hot water or steam & $9.3 \%$ & \\
\hline \multirow[t]{2}{*}{ Air conditioning } & Has $\mathrm{AC}$ & $54.5 \%$ & 22,234 \\
\hline & Does not have AC & $45.5 \%$ & \\
\hline \multirow[t]{2}{*}{ Government grant } & Government grant received & $47.0 \%$ & 3,256 \\
\hline & Government grant not received & $53.0 \%$ & \\
\hline
\end{tabular}

${ }^{\mathrm{a}}$ Weighted descriptive statistics 


\section{Results and discussion}

Lights

In 2013, 89.4\% of Canadians claimed having at least one of the energy saving lighting types whereas $10.6 \%$ of Canadians claimed to not have any of the energy-saving lighting types. As shown in Table 3, compact fluorescents were the most popular type of energy saving-light followed by fluorescent tubes and LED holiday lights.

Table 3 Percentage of households with energy saving lights by lighting type in Canada in 2013 (weighted)

\begin{tabular}{lcc}
\hline Type of energy-saving light & Yes & No \\
\hline Compact fluorescent & 73.0 & 27.0 \\
Fluorescent tubes & 41.2 & 58.8 \\
LED holiday lights & 40.0 & 60.0 \\
Halogen lights & 36.8 & 63.2 \\
Other types of LEDs & 13.8 & 86.2 \\
\hline
\end{tabular}

An 11-predictor logistic regression was fitted to the data to test the research hypothesis regarding the relationship between the likelihood of Canadian households adopting energy-saving lights, their demographics, province of residence, homeownership, and several dwelling characteristics. Overall, the independent and control variables explain $15.2 \%$ of the variance in the model. Further, the Hosmer-Lemeshow test yielded a $X^{2}(8)$ of 11.03 and was not significant $(p>0.05)$, suggesting that the model fitted the data well.

The coefficients relating to household type indicate that senior-only households as well as households composed of middle age adults, children, and seniors are more likely to have energy-saving lights than households composed strictly of middle age adults. After controlling for education, household income, household size, province of residence, homeownership, dwelling type, and other dwelling characteristics, senior only households have 59\% higher odds of having energy-saving lights than middle age-only households. Similarly, households composed of middle age adults, children, and seniors have $31 \%$ higher odds of having energy-saving lights than middle age-only households, controlling for all other model variables.

The odds ratio for education shows that when the highest level of education ever completed by any member of the household is high school or less, households have $40 \%$ lower odds of having energy-saving lights than households with members who completed university, controlling for all other model variables. Conversely, when the highest level of education ever completed by any member of the household is some postsecondary, postsecondary certificate, or diploma, households have $28 \%$ higher odds of having energy-saving lights than households in which the highest level of education attained by any member is university, controlling for all other model variables.

The model shows that the odds of having energy-saving lights substantially increase when household income belongs in the highest income bracket. Specifically, the odds ratio for household income shows that making less than $\$ 40,000$ is associated with a $59 \%$ decrease in the odds of having energy-saving lights compared to households making $\$ 80,000$ or more, controlling for the other variables in the model. Similarly, the odds ratio shows that making between $\$ 40,000$ and $\$ 80,000$ is associated with a $47 \%$ decrease in the odds of having energy-saving lights compared to households making $\$ 80,000$ or more, controlling for the other variables in the model.

Interestingly, the odds ratio for household size shows that having four or more persons in your home is associated with a $48 \%$ increase in the odds of having energy-saving lights compared to one-person households, after controlling for all model variables. Coefficients for two- and three-person households are not significant.

In addition to the demographic variables, we found that homeowners are more likely to have energy-saving lights than those who are not homeowners; homeowners are 2.77 times more likely to have energy-saving lights than non-homeowners, controlling for education, household income, household size, province of residence, dwelling type, and the other dwelling characteristics (Table 4). 
Table 4 Logistic regression predicting the odds of households having energy-saving lights

\begin{tabular}{|c|c|c|c|}
\hline Variable & $\beta$ & $S E$ & $\operatorname{Exp}(\beta)$ \\
\hline \multicolumn{4}{|l|}{ Province of residence ${ }^{a}$} \\
\hline Maritimes & 0.23 & 0.13 & \\
\hline Prairies & -0.19 & 0.09 & 0.83 \\
\hline Quebec & -0.05 & 0.09 & \\
\hline British Columbia & 0.17 & 0.11 & \\
\hline Homeowner & 1.0 & 0.08 & 2.77 \\
\hline Dwellings, other than apartment & 0.11 & 0.08 & \\
\hline \multicolumn{4}{|l|}{ Duration of residence ${ }^{b}$} \\
\hline 5 to less than 10 years & 0.19 & 0.08 & 1.21 \\
\hline 10 to less than 20 years & 0.08 & 0.08 & \\
\hline 20 to less than 30 years & 0.43 & 0.13 & 1.54 \\
\hline More than 30 years & -0.10 & 0.12 & \\
\hline \multicolumn{4}{|l|}{ Vintage $^{c}$} \\
\hline Before 1960 & -0.06 & 0.09 & \\
\hline Between 1961 and 1977 & 0.16 & 0.10 & \\
\hline Between 1978 and 1995 & -0.02 & 0.09 & \\
\hline \multicolumn{4}{|l|}{ Heating equipment $^{\mathrm{d}}$} \\
\hline Electric baseboards & -0.11 & 0.09 & \\
\hline Heating stove, heat pump, electric radiant & -0.28 & 0.12 & 0.76 \\
\hline Boiler with hot water or steam & -0.17 & 0.11 & \\
\hline Air conditioning & 0.20 & 0.07 & 1.22 \\
\hline \multicolumn{4}{|l|}{ Household composition $^{\mathrm{e}}$} \\
\hline Middle age adults with children & 0.07 & 0.12 & \\
\hline Seniors only & 0.47 & 0.09 & 1.59 \\
\hline Middle age adults, children, and seniors & 0.27 & 0.14 & 1.31 \\
\hline \multicolumn{4}{|l|}{ Education $^{\mathrm{f}}$} \\
\hline High school or less & -0.51 & 0.07 & 0.60 \\
\hline $\begin{array}{l}\text { Some postsecondary, postsecondary } \\
\text { certificate, or diploma }\end{array}$ & 0.24 & 0.08 & 1.28 \\
\hline \multicolumn{4}{|l|}{ Household income $\mathrm{g}^{\mathrm{g}}$} \\
\hline Less than $\$ 40,000$ & -0.89 & 0.10 & 0.41 \\
\hline$\$ 40,000$ to less than $\$ 80,000$ & -0.64 & 0.09 & 0.53 \\
\hline \multicolumn{4}{|l|}{ Household size ${ }^{\mathrm{h}}$} \\
\hline Two persons & 0.14 & 0.08 & \\
\hline Three persons & -0.06 & 0.12 & \\
\hline Four or more persons & 0.39 & 0.14 & 1.48 \\
\hline Constant & 1.88 & & \\
\hline Nagelkerke pseudo- $\mathrm{R}^{2}$ & 0.152 & & \\
\hline
\end{tabular}

Source. 2013 Household and the Environment Survey

Note. Odds ratios are presented only for variables that have a statistically significant effect on the dependent variable $(p<0.05) . N$ included in model $=15,907$

${ }^{\mathrm{a}}$ Reference group: Ontario

${ }^{\mathrm{b}}$ Reference goup: Respondent has lived in their residence for less than 5 years

${ }^{\mathrm{c}}$ Reference group: After 1996

${ }^{\mathrm{d}}$ Reference group: Forced air furnace

${ }^{\mathrm{e}}$ Reference group: Middle age adults only

${ }^{f}$ Reference group: University

${ }^{g}$ Reference group: More than $\$ 80,000$

${ }^{\mathrm{h}}$ Reference group: One person 
Approximately $57 \%$ of households responded "yes" to having a programmable thermostat while $43 \%$ of households responded "no". Similar to energy-saving lights, an 11-predictor logistic regression was fitted to the data to test the research hypothesis regarding the relationship between the likelihood of Canadian households adopting programmable thermostats, their demographics, province of residence, homeownership, and several dwelling characteristics. Overall, the independent and control variables explain $24.7 \%$ of the variance in the model. For this model, the Hosmer-Lemeshow test was significant $(p<0.05)$; however, this test cannot always be regarded as the best indicator for assessing goodness of fit (Allison, 2014). Additionally, 70.4\% of cases were classified correctly.

As shown in Table 5, households composed of middle age adults with children are substantially more likely to have programmable thermostats. After controlling for education, household income, household size, province of residence, homeownership, dwelling type, and other dwelling characteristics, middle age adults with children have $31 \%$ higher odds of having programmable thermostats than households composed strictly of middle age adults.

The coefficients relating to education indicate that households are less likely to have programmable thermostats in which the highest level of education attained by any member is less than university. In particular, when the highest level of education ever completed by any member of the household is high school or less, households have $16 \%$ lower odds of having a programmable thermostat compared to households in which the highest level of education is university, controlling for all other model variables. Similarly, when the highest level of education ever completed by any member of the household is some postsecondary, postsecondary certificate, or diploma, households have 19\% lower odds of having a programmable thermostat, compared to households in which the highest level of education is university, controlling for all other model variables.

The model shows that the odds of having a programmable thermostat substantially increase for households with higher incomes. Specifically, the odds ratio for household income shows that making less than $\$ 40,000$ is associated with a $26 \%$ decrease in the odds of having a programmable thermostat compared to households making $\$ 80,000$ or more, controlling for the other variables in the model. Similarly, the odds ratio shows that making between $\$ 40,000$ and $\$ 80,000$ is associated with a $33 \%$ decrease in the odds of having a programmable thermostat compared to households making $\$ 80,000$ or more, controlling for the other variables in the model.

Similar to energy-saving lights, the odds ratio for household size shows that having several occupants is associated with an increase in the odds of having a programmable thermostat. In particular, two- and three-person households are both associated with a $16 \%$ increase in the odds of having a programmable thermostat compared to one-person households, after controlling for the other model variables.

Additionally, homeowners have $77 \%$ higher odds of having a programmable thermostat compared to nonhomeowners, controlling for demographics, province of residence, and dwelling characteristics. The coefficients for vintage indicate that households living in older dwelling are less likely to have programmable thermostats. The model shows that households living in dwellings built before 1960 have 27\% lower odds of having a programmable thermostat compared to dwellings built after 1996, controlling for all other variables in the model. Households living in dwellings built between 1961 and 1977 have 24\% lower odds of having a programmable thermostat compared to dwellings built after 1996, controlling for all other variables in the model. Finally, households, living in dwellings built between 1978 and 1996 have 11\% lower odds of having a programmable thermostat compared to dwellings built after 1996, controlling for all other variables in the model. Thus it appears that the odds of having a programmable thermostat increase with each year of construction. With respect to heating equipment, the odds of having a programmable thermostat are lower for households who do not have a forced air furnace. Specifically, all groups (i.e., households with electric baseboards, heating stoves, heat pumps, and radiant heating, and households with boilers with hot water or steam) have lower odds of having a programmable thermostat compared to households that have a forced air furnace for their main heating equipment, controlling for all other model variables. Our model also shows differences in the uptake of programmable thermostats according to province. It is worth noting that households in the province of Quebec have 69\% higher odds of having a programmable thermostat compared to the province of Ontario (the reference group). This may be explained by Quebec's predominance for using electricity for heating, compared to other provinces, and that electric systems lend themselves to faster responses for setbacks. 
Table 5 Logistic regression predicting the odds of households having programmable thermostats

\begin{tabular}{|c|c|c|c|}
\hline Variable & $\beta$ & $S E$ & $\operatorname{Exp}(\beta)$ \\
\hline \multicolumn{4}{|l|}{ Province of residence $^{\mathrm{a}}$} \\
\hline Maritimes & -0.85 & 0.08 & 0.43 \\
\hline Prairies & -0.19 & 0.06 & 0.83 \\
\hline Quebec & 0.53 & 0.06 & 1.69 \\
\hline British Columbia & -0.47 & 0.07 & 0.63 \\
\hline Homeowner & 0.57 & 0.06 & 1.77 \\
\hline Dwellings, other than apartment & 0.72 & 0.06 & 2.06 \\
\hline \multicolumn{4}{|l|}{ Duration of residence ${ }^{\mathrm{b}}$} \\
\hline 5 to less than 10 years & 0.19 & 0.06 & 1.21 \\
\hline 10 to less than 20 years & -0.12 & 0.05 & 0.89 \\
\hline 20 to less than 30 years & -0.27 & 0.07 & 0.76 \\
\hline More than 30 years & -0.40 & 0.08 & 0.67 \\
\hline \multicolumn{4}{|l|}{ Vintage $^{c}$} \\
\hline Before 1960 & -0.32 & 0.06 & 0.73 \\
\hline Between 1961 and 1977 & -0.28 & 0.06 & 0.76 \\
\hline Between 1978 and 1995 & -0.12 & 0.06 & 0.89 \\
\hline \multicolumn{4}{|l|}{ Heating equipment ${ }^{\mathrm{d}}$} \\
\hline Electric baseboards & -0.93 & 0.06 & 0.40 \\
\hline Heating stove, heat pump, electric radiant & -0.53 & 0.07 & 0.60 \\
\hline Boiler with hot water or steam & -0.82 & 0.08 & 0.44 \\
\hline Air conditioning & 0.53 & 0.04 & 1.69 \\
\hline \multicolumn{4}{|l|}{ Household composition ${ }^{\mathrm{e}}$} \\
\hline Middle age adults with children & 0.27 & 0.70 & 1.31 \\
\hline Seniors only & 0.09 & 0.06 & \\
\hline Middle age adults, children, and seniors & 0.07 & 0.07 & \\
\hline \multicolumn{4}{|l|}{ Education $^{\mathrm{f}}$} \\
\hline High school or less & -0.17 & 0.05 & 0.84 \\
\hline $\begin{array}{l}\text { Some postsecondary, postsecondary } \\
\text { certificate, or diploma }\end{array}$ & -0.21 & 0.05 & 0.81 \\
\hline \multicolumn{4}{|l|}{ Household income ${ }^{\mathrm{g}}$} \\
\hline Less than $\$ 40,000$ & -0.31 & 0.06 & 0.74 \\
\hline$\$ 40,000$ to less than $\$ 80,000$ & -0.40 & 0.05 & 0.67 \\
\hline \multicolumn{4}{|l|}{ Household size $^{\mathrm{h}}$} \\
\hline Two persons & 0.15 & 0.05 & 1.16 \\
\hline Three persons & 0.15 & 0.08 & 1.16 \\
\hline Four or more persons & 0.16 & 0.08 & \\
\hline Constant & -0.22 & & \\
\hline Nagelkerke pseudo- $\mathrm{R}^{2}$ & 0.247 & & \\
\hline
\end{tabular}

Source. 2013 Household and the Environment Survey.

Note. Odds ratios are presented only for variables that have a statistically significant effect on the dependent variable $(p<.005) . N$ included in model $=14,745$

${ }^{\mathrm{a}}$ Reference group: Ontario.

${ }^{b}$ Reference goup: Respondent has lived in residence for less than 5 years

${ }^{c}$ Reference group: After 1996

${ }^{\mathrm{d}}$ Reference group: Forced air

${ }^{\mathrm{e}}$ Reference group: Middle age adults only

${ }^{\mathrm{f}}$ Reference group: University

${ }^{g}$ Reference group: More than $\$ 80,000$

${ }^{\mathrm{h}}$ Reference group: One person 
Audits

For the subsample who responded yes to an energy audit having been conducted for their dwelling, and answering yes to the energy audit having been conducted in the past 10 years, approximately $62 \%$ of respondents reported making changes as a result of the audit while nearly $38 \%$ of households did not. A 12 -predictor logistic regression was fitted to the data to test the research hypothesis regarding the relationship between the likelihood of Canadian households making changes to their household's dwelling as a result of an energy audit, their demographics, province of residence, homeownership, several dwelling characteristics, and whether or not a government grant was received as part of a home energy retrofit program. Overall, the independent and control variables explain $44.1 \%$ of the variance in the model. Further, the Hosmer-Lemeshow test yielded a $X^{2}(8)$ of 14.49 and was not significant $(p>$ 0.05 ), indicating that the null hypothesis of a good model fit to the data was acceptable.

The coefficients relating to household type indicate that senior only households as well as households composed of middle age adults with children are less likely to make changes to their dwelling after conducting an energy audit than households composed strictly of middle age adults. After controlling for education, household income, household size, province of residence, homeownership, dwelling type, other dwelling characteristics, and whether or not a government grant was received, senior only households have $44 \%$ lower odds of making changes to their dwelling than middle age only households. Similarly, households composed of middle age adults with children have $32 \%$ lower odds of making changes to their dwelling than middle age only households, controlling for all other model variables.

The odds ratio for education shows that households in which the highest level of education ever completed by any member of the household is some postsecondary, postsecondary certificate, or diploma is associated with a $25 \%$ decrease in the odds of making dwelling changes after conducting an energy audit, after controlling for the other variables in the model.

The coefficients relating to household size indicate that larger households are more likely to make changes to their dwelling after conducting an energy audit than one-person households. In particular, two-person households have $61 \%$ higher odds of making changes to their dwelling compared to one-person households, controlling for all other model variables. Similarly, four-person or more households are 2.58 times more likely to make changes to their dwelling compared to one-person households, controlling for all other model variables.

Though we are primarily interested in the relationship between demographics and changes made to dwellings resulting from energy audits, a few of the control variables seem particularly important. First, this model demonstrates that households who received a government grant as part of a home energy retrofit program are almost 9 times more likely to make changes to their dwelling as a result of an energy audit, compared to households who did not received a government grant, controlling for all other variables in the model. Further, the coefficients relating to vintage indicate that households living in older dwellings are more likely to make changes to their dwelling after conducting an energy audit than households living in dwellings constructed more recently. After controlling for all other model variables, dwellings that were built before 1960 are 8.6 times more likely to make changes to their dwelling compared to dwellings built after 1996. Dwellings built between 1961 and 1977 are 7.6 times more likely to make changes to their dwelling compared to dwellings built after 1996 and dwellings built between 1978 and 1995 are 4.9 times more likely to make changes, compared to dwellings built after 1996 (Table $6)$. 
Table 6 Logistic regression predicting the odds of households making changes due to an energy audit

\begin{tabular}{|c|c|c|c|}
\hline Variable & $\beta$ & $S E$ & $\operatorname{Exp}(\beta)$ \\
\hline \multicolumn{4}{|l|}{ Province of residence $^{\mathrm{a}}$} \\
\hline Maritimes & 0.60 & 0.25 & 1.82 \\
\hline Prairies & -0.04 & 0.19 & \\
\hline Quebec & -0.29 & 0.18 & \\
\hline British Columbia & 0.17 & 0.24 & \\
\hline Homeowner & 0.62 & 0.22 & 1.86 \\
\hline Dwellings, other than apartment & 0.25 & 0.24 & \\
\hline \multicolumn{4}{|l|}{ Duration of residence $^{\mathrm{b}}$} \\
\hline 5 to less than 10 years & 0.85 & 0.18 & 2.33 \\
\hline 10 to less than 20 years & 0.99 & 0.18 & 2.69 \\
\hline 20 to less than 30 years & 0.51 & 0.21 & 1.67 \\
\hline More than 30 years & 0.20 & 0.22 & \\
\hline \multicolumn{4}{|l|}{ Vintage $^{c}$} \\
\hline Before 1960 & 2.15 & 0.20 & 8.60 \\
\hline Between 1961 and 1977 & 2.03 & 0.19 & 7.60 \\
\hline Between 1978 and 1995 & 1.58 & 0.19 & 4.90 \\
\hline \multicolumn{4}{|l|}{ Heating equipment ${ }^{\mathrm{d}}$} \\
\hline Electric baseboards & 0.29 & 0.18 & \\
\hline Heating stove, heat pump, electric radiant & 0.20 & 0.21 & \\
\hline Boiler with hot water or steam & 0.27 & 0.25 & \\
\hline Air conditioning & 0.27 & 0.13 & 1.31 \\
\hline Government grant for energy audit & 2.17 & 0.13 & 8.80 \\
\hline \multicolumn{4}{|l|}{ Household composition $^{\mathrm{e}}$} \\
\hline Middle age adults with children & -0.39 & 0.19 & 0.68 \\
\hline Seniors only & -0.58 & 0.17 & 0.56 \\
\hline Middle age adults, children, and seniors & -0.10 & 0.20 & \\
\hline \multicolumn{4}{|l|}{ Education $^{\mathrm{f}}$} \\
\hline High school or less & 0.20 & 0.17 & \\
\hline $\begin{array}{l}\text { Some postsecondary, postsecondary certificate, } \\
\text { or diploma }\end{array}$ & -0.29 & 0.13 & 0.75 \\
\hline \multicolumn{4}{|l|}{ Household income $^{\mathrm{g}}$} \\
\hline Less than $\$ 40,000$ & 0.03 & 0.19 & \\
\hline$\$ 40,000$ to less than $\$ 80000$ & -0.01 & 0.14 & \\
\hline \multicolumn{4}{|l|}{ Household size $^{\mathrm{h}}$} \\
\hline Two persons & 0.48 & 0.17 & 1.61 \\
\hline Three persons & -0.21 & 0.23 & \\
\hline Four or more persons & 0.95 & 0.25 & 2.58 \\
\hline Constant & -3.53 & & \\
\hline Nagelkerke pseudo- $\mathrm{R}^{2}$ & 0.441 & & \\
\hline
\end{tabular}

Source. 2013 Household and the Environment Survey

Note. Odds ratios are presented only for variables that have a statistically significant effect on the dependent variable $(p<0.05) . N$ included in model $=2,257$

${ }^{a}$ Reference group: Ontario

${ }^{b}$ Reference goup: Respondent has lived in residence for less than 5 years

${ }^{\mathrm{c}}$ Reference group: After 1996

${ }^{\mathrm{d}}$ Reference group: Forced air

${ }^{\mathrm{e}}$ Reference group: Middle age adults only

${ }^{\mathrm{f}}$ Reference group: University

${ }^{g}$ Reference group: More than $\$ 80,000$

${ }^{\mathrm{h}}$ Reference group: One person 
The results suggest that demographic characteristics contribute, in part, to household adoption of energy efficiency measures. Our findings are thus comparable to the energy consumption literature (e.g., Huebner, Hamilton, Chalabi, Shipworth, \& Oreszczyn, 2015; Santin, 2011) in that demographic characteristics are important for predicting both energy consumption and energy efficiency. Although related, these are very different arenas of research given that the impact of similar demographic characteristics can vary across both areas of research. For example, higherincome households are likely to use more energy than lower-income households but these same higher-income households also have more potential to invest in energy efficiency (Abrahamse \& Steg, 2009). The current findings are therefore important for demonstrating not only how Canadians are using energy, but more specifically, the characteristics that contribute to the efficient use of energy.

Our findings demonstrate that age and household composition appear to be relevant for the technologies that were analyzed and for the choices surrounding energy-efficient dwelling changes. It appears that households with seniors adopt energy-saving lights the most, whether they are senior-only households or extended households formed of middle age adults with children and seniors. Interestingly, it is possible that seniors are driving the adoption of energy-saving lights. Earlier studies confirm that the probability of investing, or entry into the market, increases with age for energy-efficient lighting and is higher among retired persons (Ameli \& Brandt, 2015; Mills \& Schleich, 2010). For programmable thermostats, younger families have higher odds of adoption and our findings are in line with similar research examining the role of age and family type in choosing various energy-efficient technologies (e.g., Mills \& Schleich, 2012). With respect to making dwelling changes after conducting an energy audit, it appears that senior-only households and households composed of middle age adults with children are making changes the least. Here it is possible that seniors and families are less interested in the potentially very involved upgrades or installations associated with efficiency dwelling changes. The public use microdata file that was used in this analysis did not specify the types of dwelling changes that households could make after conducting an energy audit; however, we believe that it is safe to assume that some of these changes would be less difficult and less involved, such as caulking or weather stripping, and some of the changes would be more difficult and more involved, such as installing new heating systems. Although Ameli and Brandt (2015) found that the probability of investment in heat thermostats, thermal insulation, and energy-efficient windows increases with age, they and others confirm that the probability of investing declines with age for more innovative changes (Ameli \& Brandt, 2015; Mahapatra \& Gustavsson, 2008). Even more, research demonstrates that households with older members demonstrate preference for older style heating systems (Michelsen \& Madlener, 2012). Similarly, it is possible that the seniors in this study are also demonstrating less inclination for the more "innovative" energy efficiency retrofits. It is also possible that the seniors in this study are making decisions based on a cost-benefit analysis, accounting for life expectancy.

Generally, the results here show that lower levels of education decrease the odds of adopting technology and making dwelling changes and are similar to the results of other studies (Mills \& Schleich, 2012; Michelsen \& Madlener, 2012; Sardianou \& Genoudi, 2013). Interestingly, we found for households where the highest level of education ever completed by any member of the household is some postsecondary, postsecondary certificate, or diploma, the adoption of energy-saving lights increases, compared to university-level educated households. Though researchers are often limited to certain types of datasets and variable information, such as in national surveys, both future surveys and studies should collect more information on different levels of education to examine possible nuances for the effects of education. For both programmable thermostats and dwelling changes, households having members with less than a university level of education significantly reduce the odds of adoption and this effect is similar to other research showing the effect of education on the adoption of different types of technology (Mills and Schleich (2012). These results suggest that certain types of technology adoption and retrofit behavior appeal to more educated households and could be related to being curious about innovation as suggested in previous findings (Michelsen \& Madlener, 2012; Sardianou \& Genoudi, 2013). It is also possible that higher levels of education are associated with an openness for change, which is plausibly connected to technology adoption and energy efficiency. These types of findings imply that education is an important factor and should be leveraged through educational programs on energy consumption, generally, as well as energy efficiency, more specifically.

With the exception of dwelling changes resulting from energy audits, our results for income are very similar to other research demonstrating that higher levels of household income correspond to higher levels of energy efficiency adoption (Ameli \& Brandt, 2015; Michelsen \& Madlener, 2012; Nair et al., 2010). Although we found no effect of income on dwelling changes, households who received a government grant as part of a home energy retrofit program were substantially more likely to make changes to their dwelling as a result of an energy audit, compared to households who did not receive a government grant. As such, the driving force behind dwelling changes may not be income, but rather the provisioning of incentives. In Canada energy efficiency incentives or grants can be supported 
by municipal, provincial/territorial government programs, as well as electric and gas utility programs (Natural Resources Canada, n.d.). Typically, not all capital costs are covered but a substantial amount can be, depending on the scope of the work. In this study we controlled for income, and, potentially, capital constraints, which would theoretically decrease as income increased. As such, it appears that grants incentivize across levels of income. This strengthens evidence pertaining to the importance of financial incentives for dwelling changes and retrofits, and is bound to be impactful as higher-income households use more energy per capita. This result also suggests that instead of relieving a capital-constraint, that rebates either address an information deficit, and/or demonstrate the motivational power of economic incentives, irrespective of their proportional relationship to a person's income. We recommend that programs keep offering incentives for encouraging the adoption of energy efficiency measures.

In this study we were limited to three income categories however future research could benefit from looking at differences between various income categories to examine if there is a linear trend, overall, or if the effect of household income is slightly more nuanced as in Mills and Scleich (2010). Even more, some studies suggest that middle-income households may be the most likely to save on energy because lower-income households may be unable to further reduce their energy use and higher-income households may not want to reduce their energy use (Verhage, 1980). More research may provide stronger evidence in this area.

Similar to Ameli and Brandt (2015) and Mills and Scheich (2010), we found that increases in the number of household members generally lead to more energy efficiency adoption. Therefore, while larger sized households generally use more energy, they may also adopt more measures of energy efficiency. There is limited research in this area but possibly an explanation for this phenomenon is that as the number of people in a household increase, so do the motivations to be more energy efficient, which may translate into energy efficiency behavior. Another explanation for this behavior may come from community-based social marketing wherein the power of influencing one's neighbor can be extended to the power of influencing a household member (McKenzie-Mohr, 2011).

Apart from demographic determinants, it is clear that individuals who own their homes versus individuals who do not, respond differently to measures of energy efficiency. Across all three observed measures of energy efficiency, homeowners versus renters were more likely to adopt the technology or to make dwelling changes. This type of finding is not surprising given the issue of split incentives (or principal-agent problems) whereby differing incentives can lead to different behaviors between owner-occupied households and renter-occupied households (Gillingham, Harding, \& Rapson, 2012). For example, renters may choose to underinvest in measures of energy efficiency due to capital constraints and/or short housing tenures because they may not benefit from the financial returns on their investments. In our modeling, we controlled for both household income (and therefore capital constraints) as well as housing tenure and still found that homeowners were more likely to adopt energy efficiency technology or to make dwelling changes. For many renters, utilities are included in the rent, i.e., they are paid by the owner. As such, it is possible that even after controlling for tenure and income, renters who do not pay directly for their utilities may be less motivated by measures of energy efficiency given that they will not experience direct financial benefits. Further, renters who do not pay for their utilities may misperceive their housing costs leading to higher-temperature settings, more frequent use of air conditioning, and at cooler temperatures, as well as adopting fewer measures of energy efficiency. The issue of energy 'invisibility' may be addressed by assisting households and occupants with monitoring their energy usage. With more and more smart meters being rolled out across the country, there is an opportunity for tracking energy usage. Further, if households are motivated to participate in energy efficiency and need feedback for encouragement, home energy displays could be a solution. We also suggest that many renters may be unaware of their plans for a housing tenure prior to renting a dwelling. For example, while on paper a renter may have lived in the same place for 6 years, it is plausible that this was an initial 1-year commitment, followed by a series of ad hoc extensions of their tenure. In this way, the 6-year tenure is spilt up into segments which would lend itself to less invenstment in the property than their 6-year tenure would suggest.

It is important to note that the examination of the energy efficiency gap in terms of financial costs and benefits (e.g., Jaccard \& Dennis, 2006) has received criticism (Wilson, Crane, \& Chyrssochoidis, 2012). Many argue that the energy efficiency gap has been incorrectly conceptualized and reduced to a question of rationality that assumes individuals to be motivated decision-makers who are occupants living in dwellings rather than individuals who share homes (Maller \& Horne, 2011; Shove, 1998). Conversely, a sociological lens argues for examining energy efficiency and, specifically, renovations through the view of routine, every day, and shared practices that constitute home life (Wilson et al., 2012). In particular, renovations consist of periodic or ongoing features of domestic life rather than a one-off event (Fawcett, 2014). As such, households and families may choose not to adopt measures of energy efficiency, not because of financial constraints, but due to the disruption such decisions may lead to or because of their existing relationship with their home, which may prevent making changes. Furthermore, a lack of motivation to be energy efficient may be influenced by personal-level variables. These can include attitudes toward and beliefs about energy use or energy efficiency and the environment (Stern, 2000). These social science perspectives are important to note as they may help with better understanding the phenomenon of household energy 
efficiency. As such, future large-scale surveys and research need to incorporate these types of questions and relevant variables into their research.

Overall, our results are in line with findings from other studies but our findings regarding seniors are particularly interesting. We notice that senior households appear to be interested in energy efficiency as seen from their adoption of energy-saving lights, more so than other household types. However, the same group of seniors does not appear to be making changes to their dwellings after conducting energy audits. Thus, it appears that this group is interested in measures of energy efficiency but not all available measures of energy efficiency. Due to the increasing number of senior households, the high percentage of older homeowners, and what appears to be a preference for aging in the home, rather than in out-of-home care facilities (Sabia, 2008), research on energy efficiency among senior households needs to continue. In 2013, 71\% of Canadians aged 65 to 74 owned their homes while $70.5 \%$ of those aged 75 to 84 owned their homes (CMHC, 2012). Further, approximately $85 \%$ of Canadians 55 years and older want to remain in their homes for as long as possible, even if they experience changes to their health (CMHC, 2008). Older studies have been conducted on this demographic and have found that aging and adoption of energy conservation and efficiency are, generally, negatively associated (Berry \& Brown, 1988; Berry \& Schweitzer, 1991; Brown \& Rollinson, 1985). However, more up-to-date work needs to address this group's behaviors. In particular, future energy transitions that incorporate energy innovation will need all types of households to participate, including senior households. Therefore, research needs to continue given the implications in the current changing energy landscape.

\section{Conclusion}

In Canada, there are more households, homes are larger with less people in them, and there are more appliances per household. Even more, as with other countries, Canada's population is aging. These changes will not only influence the manner in which energy will be used but will also influence the manner in which people choose to reduce their energy use. All over, researchers and decision-makers are developing effective solutions and new technologies to increase household energy efficiency; however, their uptake will depend on and improve with a better understanding of the individuals that are being targeted. For example, aging may have direct consequences for energy efficiency if different types of age groups show preferences for different measures of energy efficiency, with some measures being more efficient than others. Although it was found that Canadian households are participating in energy efficiency, not all groups are participating equally. Therefore, our results demonstrate the need for future work to determine which efficiency behaviors individuals and households are participating in, and how best to support them in their adoption of energy efficiency.

\section{Acknowledgements}

The authors would like to thank the anonymous reviewers for their valuable comments and suggestions. Although the research and analysis are based on data from Statistics Canada, the opinions expressed do not represent the views of Statistics Canada.

\section{Conflict of interest}

The authors declare that they have no conflict of interest.

\section{References}

Abrahamse, W., \& Steg, L. (2009). How do socio-demographic and psychological factors relate to households' direct and indirect energy use and savings? Journal of Economic Psychology, 30(5), 711-720. https://doi.org/10.1016/j. joep.2009.05.006.

Abrahamse, W., \& Steg, L. (2011). Factors related to household energy use and intention to reduce it: the role of psychological and socio-demographic variables. Human Ecology Review, 18(1), 30-40.

Allison, P. D. (2014). Measures of fit for logistic regression. In SAS Global Forum, Washington, DC.

Ameli, N., \& Brandt, N. (2015). Determinants of households' investment in energy efficiency and renewables: evidence from the OECD survey on household environmental behaviour and attitudes. Environmental Research Letters, 10(4), 044015. https://doi.org/10.1088/1748-9326/10/4/044015.

Benders, R. M. J., Kok, R., Moll, H. C., Wiersma, G., \& Noorman, K. J. (2006). New approaches for household energy conservation - in search of personal household energy budgets and energy reduction options. Energy Policy, 2006(34), 3612-3622. 
Berry, L., \& Brown, M. (1988). Participation of the elderly in residential conservation programmes. Energy Policy, $16(2), 152-163$.

Berry, L., \& Schweitzer, M. (1991). Residential conservation programmes for the elderly. Marketing techniques and organizational structures. Energy Policy, 19(6), 596-605.

Biesiot, W., \& Noorman, K. J. (1999). Energy requirements of household consumption: a case study of the Netherlands. Ecological Economics, 28(3), 367-383. https://doi. org/10.1016/S0921-8009(98)00113-X.

Blackwell, R. (2015). Canada dims the light on the incandescent light bulb. The Globe and Mail. Retrieved from http://www. theglobeandmail.com/report-on-business/industry- news/energy-and-resources/canada-dimsthe-light-on-the- incandescent-light-bulb/article22739434/

Brounen, D., Kok, N., \& Quigley, J. M. (2013). Energy literacy, awareness, and conservation behavior of residential house- holds. Energy Economics, 38,42-50. https://doi.org/10.1016 /j.eneco.2013.02.008.

Brown, C., Gorgolewski, M., \& Goodwill, A. (2015). Using physical, behavioral, and demographic variables to explain suite-level energy use in multiresidential buildings. Building and Environment, 89, 308-317. https://doi.org/10.1016/j. buildenv.2015.02.039.

Brown, M. A., \& Rollinson, P. A. (1985). Residential energy consumption in low-income and elderly households: how nondiscretionar is it? Energy Systems and Policy, 9(3), 271-301.

CMHC. (2008). Impacts of the aging of the Canadian population on housing and communities. Research Highlight, Socio- Economic Series. Retrieved from www.cmhc.ca.

CMHC. (2012). Housing for older Canadians: the definitive guide to the over-55 market: Planning the Project, 1.

Fawcett, T. (2014). Exploring the time dimension of low carbon retrofit: owner-occupied housing. Building Research \& Information, 42(4), 477-488. https://doi.org/10.1080/09613218.2013.804769.

Frederiks, E. R., Stenner, K., \& Hobman, E. V. (2015). The socio- demographic and psychological predictors of residential energy consumption: a comprehensive review. Energies, 8(1), 573-609. https://doi.org/10.3390/en8010573.

Fritzsche, D. (1981). An analysis of energy consumption patterns by stage of family life cycle. Journal of Marketing Research, 18(May), 227-232.

Gamtessa, S. F. (2013). An explanation of residential energy- efficiency retrofit behavior in Canada. Energy and Buildings, 57,155-164. https://doi.org/10.1016/j.enbuild.2012.11.006.

Gardner, G. T., \& Stern, P. C. (2008). The short list: the most effective actions U.S. households can take to curb climate change. Environment, 50,12-23.

Gatersleben, B., Steg, L., \& Vlek, C. (2002). Measurement and determinants of environmentally significant consumer behavior. Environment and Behavior, 34(3), 335-362.

Gillingham, K., Harding, M., \& Rapson, D. (2012). Split incentives in residential energy consumption. The Energy Journal, 33(2), 37.

Hicks, A. L., \& Theis, T. L. (2014). Residential energy-efficient lighting adoption survey. Energy Efficiency, 7, 323-333. https://doi.org/10.1007/s12053-013-9226-6.

Hoicka, C. E., Parker, P., \& Andrey, J. (2014). Residential energy efficiency retrofits: how program design affects participation and outcomes. Energy Policy, 65, 594-607. https://doi. org/10.1016/j.enpol.2013.10.053.

Holloway,D.,\&Bunker, R. (2006). Planning, housing and energy use: a review, urban policy and research. Urban Policy and Research, 24,115-126.

Huebner, G. M., Hamilton, I., Chalabi, Z., Shipworth, D., \& Oreszczyn, T. (2015). Explaining domestic energy consumption - the comparative contribution of building factors, socio-demographics, behaviours and attitudes. Applied Energy, 159, 589-600. https://doi.org/10.1016/j. apenergy.2015.09.028.

Jaccard,M., \& Dennis,M. (2006). Estimating home energy decision parameters for a hybrid energy-economy policy model. Environmental Modeling and Assessment, 11(2), 91-100.

Macey, S. M. (1988). Eldery consumption and the elderly. The Canadian Geographer, 2(2), 167-169.

Mahapatra, K., \& Gustavsson, L. (2008). An adopter-centric approach to analyze the diffusion patterns of innovative residential heating systems in Sweden. Energy Policy, 36(2), 577-590.

Maller, C. J., \& Horne, R. E. (2011). Living lightly: how does climate change feature in residential home improvements and what are the implications for policy? Urban Policy and Research, 29(1), 59-72.

McKenzie-Mohr, D. (2011). Fostering sustainable behavior: an introduction to community-based social marketing. Gabriola Island: New society publishers.

Michelsen, C. C., \& Madlener, R. (2012).Homeowners' preferences for adopting innovative residential heating systems: a discrete choice analysis forGermany. Energy Economics, 34(5), 1271- 1283. https://doi.org/10.1016/j.eneco.2012.06.009.

Mills, B. F., \& Schleich, J. (2010). Why don't households see the light? Explaining the diffusion of compact fluorescent lamps. Resource and Energy Economics, 32(3), 363-378. 
https://doi.org/10.1016/j.reseneeco.2009.10.002.

Mills, B., Schleich, J., \&Volume, E. P. (2012). Residential energy- efficient technology adoption, energy conservation, knowl- edge, and attitudes: an analysis of European countries. Energy Policy, 49,616-628.

Nair, G., Gustavsson, L., \& Mahapatra, K. (2010). Factors influencing energy efficiency investments in existing Swedish residential buildings. Energy Policy, 38(6), 2956- 2963. https://doi.org/10.1016/j.enpol.2010.01.033.

Natural Resources Canada. (n.d.). Retrieved from http://www. nrcan.gc.ca/energy/funding/efficiency/4947

Natural ResourcesCanada. (n.d.) Retrieved fromhttps://oee.nrcan. gc.ca/corporate/statistics/neud/dpa/data_e/glossary_e.cfm\#p

Natural Resources Canada. (2016). Energy efficiency trends in Canada 1990 to 2013.

Pan, Y., \& Jackson, R. T. (2008). Ethnic difference in the relation- ship between acute inflammation and serum ferritin in US adult males. Epidemiology and Infection, 136, 421-431.

Peffer, T., Pritoni, M., Meier, A., Aragon, C., \& Perry, D. (2011). How people use thermostats in homes: a review. Building and Environment, 46(12), 2529-2541.

Poortinga, W., Steg, L., Vlek, C., \& Wiersma, G. (2003). Household preferences for energy-saving measures: a conjoint analysis. Journal of Economic Psychology, 24(1), 49- 64. https://doi.org/10.1016/S01674870(02)00154-X.

Rea, L. M., \& Parker, R. A. (2014). Designing and conducting survey research: a comprehensive guide. San Francisco: John Wiley \& Sons.

Reid, L., Sutton, P., \& Hunter, C. (2010). Theorizing the meso level: the household as a crucible of proenvironmental behaviour. Progress in Human Geography, 34(3), 309-327.

Ritchie, J. R. B., Mcdougall, G. H. G., \& Claxton, J. D. (1981). Complexities of household energy consumption and conservation. Journal of Consumer Research, 8(3), 233-242.

Rogerson, P. A. (2001). Statistical methods for geography. London: Sage.

Sabia, J. J. (2008). There's no place like home. A hazard model analysis of aging in place among older homeowners in the PSID. Research on Aging, 30(1), 3- 35. https://doi.org/10.1177/0164027507307919.

Santin, O. G. (2011). Behavioural patterns and user profiles related to energy consumption for heating. Energy and Buildings, 43(10), 2662-2672.

Sardianou, E., \& Genoudi, P. (2013). Which factors affect the willingness of consumers to adopt renewable energies? Renewable Energy, 57, 1-4. https://doi.org/10.1016/j. renene.2013.01.031.

Shove, E. (1998). Gaps, barriers and conceptual chasms: theories of technology transfer and energy in buildings. Energy Policy, 26(15), 1105-1112.

Statistics Canada. (2011) Census of population and statistics Canada catalogue no. 98-313-XCB http://www.statcan.gc. ca/tables-tableaux/sum-som/101/cst01/famil55a-eng.htm. Accessed 23 Oct 2017.

Stern, P. C. (2000). New environmental theories: toward a coherent theory of environmentally significant behavior. Journal of Social Issues, 56(3), 407-424.

Stern, P. C., \& Gardner, G. T. (1981). Psychological research and energy policy. American Psychologist, 36(4), 329-342.

Tonn, B., \& Berry, L. (1986). Determinants of participation in home energy audit/loan programs: discrete choice model results. Energy, 11(8), 785-795.

Toronto Hydro. (n.d.). Retrived from http://www.torontohydro. com/sites/electricsystem/electricityconservation/residential ?conservation/Pages/HomeLighting.aspx

US Department of Enrgy. (n.d.). Retrieved from https://energy. gov/energysaver/thermostats

Verhage, B. J. (1980). Stimulating energy conservation: applying the business heritage of marketing. European Journal of Marketing, 14(4), 167-179.

Warriner, G. K. (1981). Electricity consumption by the elderly: policy implications. Journal of Consumer Research, $8,258-264$.

Wilson, C., Crane, L., \& Chryssochoidis, G. (2015). Why do homeowners renovate energy efficiently? Contrasting perspectives and implications for policy. Energy Research \& Social Science, 7, 12-22. 